\title{
Refining of Crude Sulfate Turpentine Obtained from a Kraft Pulp Mill: A Pilot Scale Treatment
}

\begin{abstract}
Ahsen Ezel Bildik Dal
Crude sulfate turpentine (CST), a by-product of the kraft process, has commercial value that depends on the removal of sulfur compounds. The current study investigates desulfurization of CST using basic process steps for a paper mill at a pilot scale treatment. In another aspect, the sulfurous compounds in CST were removed by passing to the aqueous phase with terpin hydrate production, followed by $\alpha$-terpineol conversion with citric acid catalysis. The goal was to design an environmentally friendly, low-cost, zero waste process and thereby refine the CST or byproducts to a quality that can produce chemical raw materials. Refining processes included hypochlorite oxidation, air oxidation, washing with water, and distillation. The sulfur content was decreased to 170, 106, and $29 \mathrm{ppm}$ from respectively by $1260 \mathrm{ppm}$ initial sulphur content of CST. The chlorine amount, due to treatment with hypochlorite oxidation, did not decrease with refining processes, even in distilled fraction. By obtaining $\alpha$ terpineol from terpin hydrate, the sulfur compounds were completely removed. According to the GS-MS analysis results, distilled sulfate turpentine (DST) as the final product of the refining process of the CST sample increased the ratio with pinenes. On the other hand, with two reaction steps by obtaining terpin hydrate from CST and then a-terpineol, pinenes were converted to $\alpha$-terpineol.
\end{abstract}

Keywords: Sulfate turpentine; Sulfur removal; CST refining; Terpin hydrate; $\alpha$-terpineol

Contact information: Department of Forest Industry Engineering, Istanbul University-Cerrahpasa, Bahcekoy/Istanbul, Turkey; ahsenezel.bildik@iuc.edu.tr

\section{INTRODUCTION}

During kraft processing, the lignocellulosic structure is digested, and crude sulfate turpentine is obtained as a by-product of delignification. In addition to carbon dioxide $\left(\mathrm{CO}_{2}\right)$, sulfur dioxide $\left(\mathrm{SO}_{2}\right)$, and nitrogen oxides ( $\left.\mathrm{NOx}\right)$ as primary emissions to air during pulp production, small amounts of total reduced sulfur (TRS) are released. These malodorous compounds and primary emissions need to be eliminated immediately due to the risk of environmental pollution. While several studies have examined the composition of reaction products, others have focused on certain products for their odor properties (Valkanas and Iconomou 1963; Williams and Whittaker 1971). The toxic sulfur compounds (dimethyl sulfide, dimethyl disulfide, dimethyl sulfoxide, hydrogen sulfide, methyl mercaptan) are consequences of the reaction of wood components and chemical substances such as $\mathrm{NaOH}$ and $\mathrm{Na}_{2} \mathrm{~S}$, known as components of white liquor (Drew and Pylant Jr. 1966; Cheremisinoff and Rosenfeld 2010; Ilichev et al. 2014). Effective control of the treatment and combustion process will reduce sulfurous emissions released into the atmosphere.

Crude sulfate turpentine (CST) and its distilled fractions usually contain high concentrations (5000 ppm and above) of sulfur compounds (Jennings 1939; Lloyd and 
Bruce 1994; Leonardos et al. 1969; Ilichev et al. 2014; Rehman et al. 2016). These compounds are transported to the distillate fraction of turpentine and adversely affect the reactions of fractions (Hamby et al. 1972). Besides, these sulfur compounds, which affect the catalysts, can hurt the yield of the final product, the quality, and industrial convenience of the components (Ilichev et al. 2014; Izmest'ev et al. 2019). The reaction of the sulfurous components are deleterious to rather than 'fraction of the turpentine include' $\alpha$-pinene, $\beta$ pinene, phellandrene, myrcene, camphene, carene, limonene, etc. Moreover, they can poison catalysts and affect yields of resultant products as chemical raw material (Hamby et al. 1972; Izmest'ev et al. 2019). For turpentine to have commercial value, these sulfurous compounds, typically known as organic sulfides and mercaptans, should be reduced or removed from CST before they enter the contents of the ingredients such as perfume, fragrance formulations (Koppenhoefer et al. 1994), cleaning products, chemical raw material, polymer production, cosmetic products (Buisman and Lange 2016; Izmest'ev et al. 2019; Sinhmar and Gogate 2020), or blends with biodiesel production (Dubey and Gupta 2018; Aguas et al. 2020; Ballesteros et al. 2020). Among the advantages of the processes to be developed in this study, it is aimed to desulfurize CST and distillate fractions in practical, economical, and environmentally friendly ways by chlorinating organic components in tolerable ratios.

The odor problems arising from manufacturing operations of kraft processing, the odor thresholds of the sulfurous odorant chemicals (Leonardos et al. 1969), and final sulphur content (Collins and Brunswick 1946; Prochazka and Foy 1958; Lloyd and Bruce 1994; Hwang et al. 1994; Wang et al. 2011; Tyurmina et al. 2017; Sinhmar and Gogate 2020) are of vital importance (Rehman et al. 2016). They need to be controlled to represent the effect of chemical purity represented in Table 1 . The limitation of ' $\mathrm{S}$ ' compounds is desired to reduce the sulfur concentration preferably less than $5 \mathrm{ppm}$ with ultra-deep desulfurization (Sinhmar and Gogate 2020) for fragrance, flavor, varnishes, etc., and for final products acceptability. An application level of $10 \mathrm{ppm}$ has been judged to be acceptable in the manufacture of flotation oil disinfectants and detergents. Since the aim of the study was to separate the sulfur components from the CST in the simplest and most economical way possible, a sulfur content of $10 \mathrm{ppm}$ was targeted as 'Maximum Acceptable Concentrations' in Table 1.

Table 1. Possible Contaminant of Sulfide Compounds that Need to be Removed

\begin{tabular}{|l|c|c|c|}
\hline \multicolumn{1}{|c|}{ 'S' Compounds } & $\begin{array}{c}\text { Boiling Point } \\
\left({ }^{\circ} \mathbf{C}\right)\end{array}$ & $\begin{array}{c}\text { Odor Threshold } \\
\text { in Air } \\
(\mathbf{p p m})\end{array}$ & $\begin{array}{c}\text { Maximum } \\
\text { Acceptable } \\
\text { Concentrations } \\
(\mathbf{p p m})\end{array}$ \\
\hline Hydrogen sulfide $\left(\mathrm{H}_{2} \mathrm{~S}\right)$ & -61.8 & 0.0040 & 10 \\
\hline Methyl mercaptan $(\mathrm{MeSH})$ & 5.8 & 0.0021 & 10 \\
\hline Dimethyl sulfide $\left(\mathrm{Me}_{2} \mathrm{~S}\right)$ & 38 & 0.0010 & - \\
\hline Dimethyl disulfide $(\mathrm{MeSSMe})$ & 118 & - & - \\
\hline
\end{tabular}

Hydrodesulfurization (a general term used for refined petroleum products) is defined as a catalytic chemical process commonly used to remove sulfur compounds from organic substances. A typical hydrodesulfurization reaction occurs in a fixed bed reactor at absolute pressures of 30 to 130 atmospheres, temperatures ranging from 300 to $400{ }^{\circ} \mathrm{C}$, generally in the presence of catalysts. Hydrodesulphurization with various catalysts such as cobalt molybdenum (CoMo) for removal of heteroatoms including $\mathrm{S}, \mathrm{O}$, and $\mathrm{N}$ has been 
adapted for the terpenic hydrocarbon process (Topsøe et al. 1996; Knuuttila 2013; Kazakov et al. 2020; Wiecka et al. 2020). The dehydrogenation process could be used for removing sulfur compounds to avoid the additional treatment of sulfate turpentine in the case of achieving selective formation of cymene (Linnekoski et al. 2014). CST was desulfurized by processing with an aqueous sodium hypochlorite solution stabilized with varying sodium hydroxide ratio (Ghinet and Orza 1967; Foran 1995). With the desulfurization process, the solution $\mathrm{pH}$ reaches the range of 11 to 12 , and desulfurization resulted in significant chlorination of unsaturated organic compounds. Effective sulfurization can be achieved by factors such as the temperature of the dispersion, efficiency of the agitator type, velocity, etc. In some trials, $\mathrm{NaClO}, \mathrm{CST}$, and $\mathrm{NaOH}$ solution with nonylphenol compounds that are precursors to the commercially important non-ionic surfactants were added to make the dispersion more effective and increase the efficiency.

Organic sulfur compounds can act as hydrogen acceptors and receive hydrogenolysis, disproportionation and reduction, as shown in Eqs. 1 through 3 (Linnekoski et al. 2014).

$$
\begin{aligned}
& \mathrm{CH}_{3} \mathrm{SH}+\mathrm{H}_{2} \rightarrow \mathrm{CH}_{4}+\mathrm{H}_{2} \mathrm{~S} \text { (hydrogenolysis) } \\
& 2 \mathrm{CH}_{3} \mathrm{SH} \rightarrow\left(\mathrm{CH}_{3}\right)_{2} \mathrm{~S}+\mathrm{H}_{2} \mathrm{~S} \text { (disproportionation) } \\
& \left(\mathrm{CH}_{3}\right)_{2}+2 \mathrm{H}_{2} \rightarrow 2 \mathrm{CH}_{4}+\mathrm{H}_{2} \mathrm{~S} \text { (reduction) }
\end{aligned}
$$

Turpentine is a mixture of unsaturated, bicyclic terpene hydrocarbons, monoterpene hydrocarbons, and also contains monocyclic dipentene (Gscheidmeier and Fleig 1996; Anonymous 2002). The varying percentage of these components mainly depends on the treatment process and the origin of the tree (Drew and Pylant Jr. 1966). There are even differences in chemical composition between sulfate turpentines produced in summer and winter seasons (Miller 1970; Ucar et al. 2000).

A method has been developed to describe the practical maximum efficiency of desulfurization with an aqueous solution of the alkaline earth divalent ions as $\mathrm{Na}, \mathrm{K}, \mathrm{Ca}$, $\mathrm{Mg}$. The sequential process before distillation during the recovery of the distillate components results in increased economy and less environmental pollution compared with the previously proposed cleaning processes for CST and its distillate fractions (Vital et al. 1992; Pakdel et al. 2001). In addition, the purification of crude sulfate turpentine, terpin hydrate and $\alpha$-terpineol were obtained. In contrast, the common approach for synthesis of $\alpha$-terpineol from CST (Pakdel et al. 2001) was employed. Thus, $\alpha$-terpineol transition was made from terpin hydrate in this study. In addition, with the refining process, high purity sulfate turpentine and its derivatives were obtained with high efficiency and low energy consumption. Besides, high-efficiency $\alpha$-terpineol was obtained by hydration reaction with the help of acid catalysts. In the second stage, terpin hydrate production from CST was carried out in a simple reaction step on acid catalyst. Thus, the sulfide compounds remained in the aqueous phase and an additional by-product terpin hydrate was obtained. Then, $\alpha-$ terpineol was synthesized from terpin hydrate. Thus, the disadvantages of producing $\alpha$ terpineol directly from CST were eliminated and $\alpha$-terpineol from CST without refining process were compared. Sulfurous compounds remained in the aqueous phase during terpin hydrate production, and it was aimed to increase the efficiency of the conversion of $\alpha$ terpineol. Thus, the sulfur content is completely removed, and two different valuable byproducts were obtained. Among the advantages of the processes to be developed in this study, it is aimed to desulfurize CST and distillate fractions in practical, economical, and environmentally friendly ways by chlorinating organic components in tolerable ratios. 
Crude rosin contains monohydrate remaining after the separation of terpene hydrocarbons and alcohols by distillation, which can be separated from the medium by steam distillation. Monohydrate is most easily obtained artificially by the reaction of dilute $\mathrm{H}_{2} \mathrm{SO}_{4}$ with $\alpha$-pinene. During acid hydration of sulfur compounds, malodor is eliminated by passing into aqueous form.

Terpin hydrate is easily converted into the $\alpha$-terpineol by partial dehydration (Sell 2006; Surburg and Panten 2016). Terpin hydrate and a-terpineol, which are obtained as a result of hydration of a-pinene that is present in the turpentine after the refining of sulfate turpentine, are the most demanded turpentine derivatives (Ávila et al. 2010; Prakoso et al. 2020). Crude sulfate turpentine refiners primarily separate the purified turpentine into its main components, $\alpha$ - and $\beta$-pinene (Packer et al. 1998; Pakdel et al. 2001; Naoum et al. 2019). Subsequently, $\alpha$-pinene can be converted into $\alpha$-terpineol by hydrating under various conditions (Santos and Morgado, 2005) or from crude sulfate turpentine to $\alpha$ terpineol (Pakdel et al. 2001), $\alpha$-terpineol is produced in the presence of various catalysts, and the $\alpha$-terpineol obtained after the purification process is compared in terms of sulfur content (Pakdel et al. 2001). $\alpha$-Terpineol conversion is called sweetening and shows similarities with the refining process of CST with terpin hydrate extraction; a product may obtain directly from crude sulfate turpentine without the need for refining (Pakdel et al. 2001).

In the current study, desulfurization stages of CST, a by-product of kraft mill, with an economical and efficient method were investigated. Terpin hydrate production from CST and $\alpha$-terpineol from terpin hydrate, and sulfur components that could be completely eliminated with that method, were also examined in this respect. Thus, in addition to the removal of sulfur, $\alpha$-terpineol and terpin hydrate products can be obtained in the kraft mill.

\section{EXPERIMENTAL}

\section{Materials}

Crude sulfate turpentine (CST) samples were obtained from OYKA paper mill in Turkey. Commercial sodium hypochlorite with an active $\mathrm{pH}$ was 12 and additionally, sodium hydroxide, $\mathrm{H}_{2} \mathrm{SO}_{4}$, citric acid, nonylphenols (NP-10) were selected in the experiments. Sodium hypochlorite is preferred as an economical reagent for oxidation process.

\section{Method}

Crude sulfate turpentine was kept in a 5-ton stock tank, and the basic analyses were performed according to ASTM D889-13 (2017) and ASTM D233-13(2017). The sequential stage of sulfur removal from CST is shown in Fig. 1. As a following stage, the distillation process was operated with a pilot extractor. Samples from each of the four stages of refining CST and $\alpha$-terpineol sulfur and chlorine content were analyzed by High Definition Energy Dispersive X-Ray Fluorescence (HDXRF). The test was conducted directly without any further preparation. GC-MS analyzes of CST, DST (Distillated Sulphate Turpentine), and $\alpha$-terpineol were conducted at central laboratory at Istanbul University-Cerrahpasa. Analyses were carried out by capillary column. The temperature program was $2.00 \mathrm{~min}$ at $80{ }^{\circ} \mathrm{C}, 10^{\circ} \mathrm{C} / \mathrm{min}$ to $240{ }^{\circ} \mathrm{C}, 20^{\circ} \mathrm{C} / \mathrm{min}$ to $280{ }^{\circ} \mathrm{C}$, and $10.0 \mathrm{~min}$ at $280{ }^{\circ} \mathrm{C}$. The column flow was $1.1 \mathrm{~mL} / \mathrm{min}$. 


\section{Oxidation Process with Hypochlorite}

Sodium hypochlorite solution with $15 \%$ chlorine content and $10 \% \mathrm{NaOH}$ was prepared in the $\mathrm{pH}$ range 12 to 13 . The hypochlorite solution and crude sulfate turpentine were mixed in a $1: 1$ to $1: 0.5 \mathrm{v} / \mathrm{v}$ ratio, and 0.1 to $0.2 \%$ nonylphenol was added the dispersion with a vigorous mechanical agitator at $30^{\circ} \mathrm{C}$. NP-10 was used as an emulsifier and allowed the emulsion to be broken, with separation of the aqueous phases in $4 \mathrm{~h}$ time.

With the oxidation process with sodium hypochlorite, the impurities of the sulfurous organic compounds, which are responsible for the malodor and coloration besides causing corrosion of equipment's and pipeline in the final product of CST (Sinhmar and Gogate 2020), were converted to a water-soluble form. At the end of the period, the dispersed mixture was taken from the container and kept in a separation funnel until the two phases were separated entirely. NP-10 remained in the chlorine phase with aqueous residue. After removing the aqueous phase, the upper phase was washed several times by rinsing with warm distilled water until the $\mathrm{pH}$ was neutral and the impurities were removed.

\section{Air Oxidation}

The sample was modified by air oxidation by passing oxygen for 3 to $4 \mathrm{~h}$ with an air oxidation stage, and the sulfur and chlorine content was controlled by High-Definition X-Ray Fluorescence (HDXRF; XOS, New York, USA).

\section{Distillation}

The distillation process aimed to completely remove residual sulfur and chlorine. The deodorized turpentine at an early stage was distilled in a pilot extractor (Fig. 2). Various impurities were separated from the refined product, which was initially heated to $130^{\circ} \mathrm{C}$ until distillate and water stream ended completely. The remained sample was heated up to $180{ }^{\circ} \mathrm{C}$ with a controlled elevated temperature system. The distillated sample was collected in a 5-ton stock tank and labelled DST (Distillated Sulphate Turpentine).

\section{Terpin Hydrate Production}

$25 \% \mathrm{H}_{2} \mathrm{SO}_{4}$ solution and CST were mixed in a $4: 1 \mathrm{w} / \mathrm{w}$ ratio, then $0.1 \% \mathrm{NP}-10$ was added the dispersion at the acid-proof vigorous mechanical agitator at a constant temperature of $30^{\circ} \mathrm{C}$. NP 10 was selected as an emulsifier to provide turpentine emulsion in $\mathrm{H}_{2} \mathrm{SO}_{4}$ apart from previous studies acetone, toluene sulfonic acid used as emulators. Hence, during acid hydration of sulfur compounds, malodor is eliminated by passing into aqueous form easily.

The reaction was ended after 25 hours at constant temperature. The crystals were separated from the aqueous phase by centrifugation. The filtered crystals were washed in $10 \%$ sodium carbonate solution, the acidic parts were removed and neutralized, and then the sample was dried and weighed.

\section{$\alpha$-Terpineol Production}

$\alpha$-Terpineol was obtained in the presence of citric acid catalysts. A citric acid solution with a pH of 2.8 was prepared $20 \%$ aqueous solution and 2:1 w/w ratio terpinhydrate was added. The mixture heated and stirred at 15 hours in a reflux at atmospheric pressure in the pilot extractor (Fig. 2). 


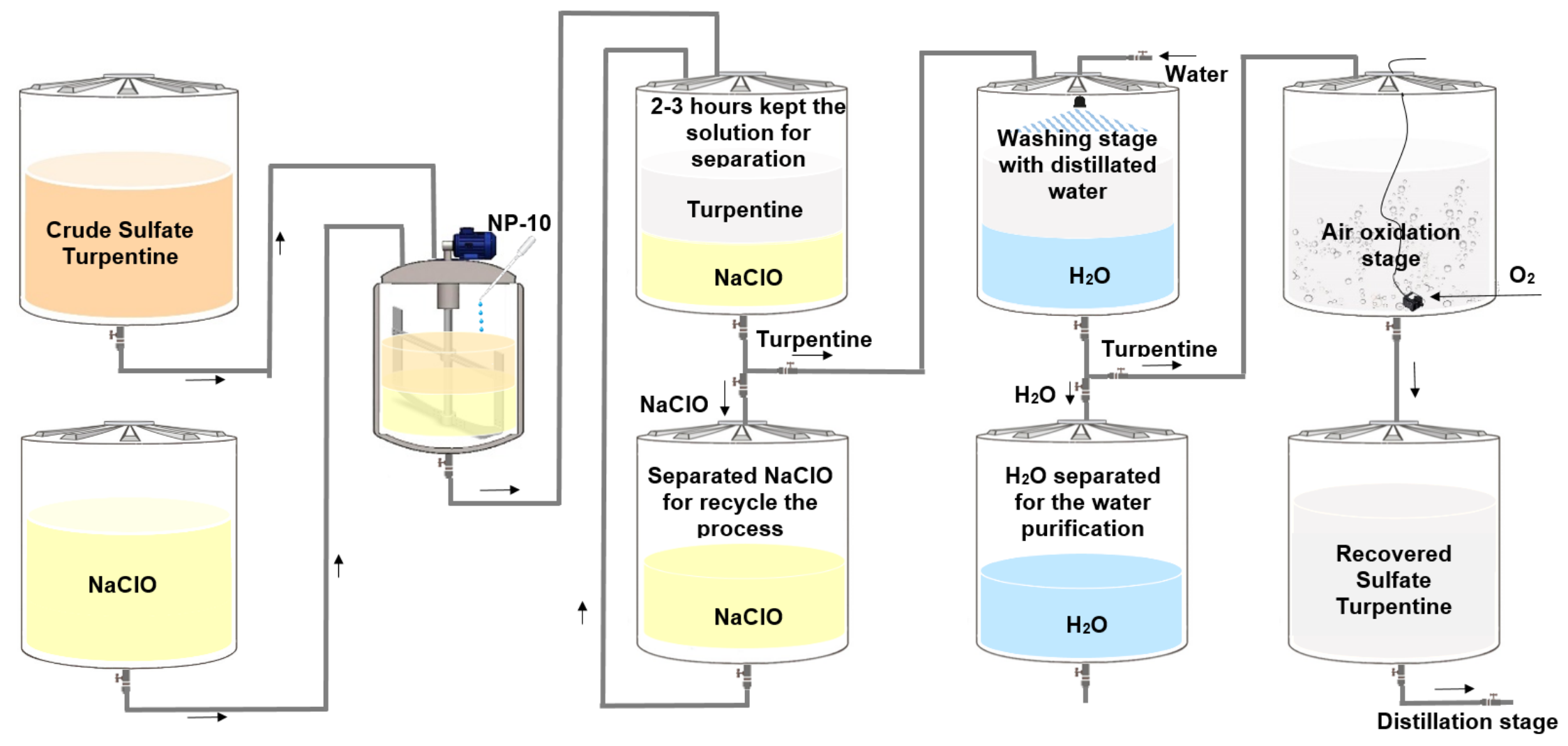

Fig. 1. Sulphur removing stages from CST 


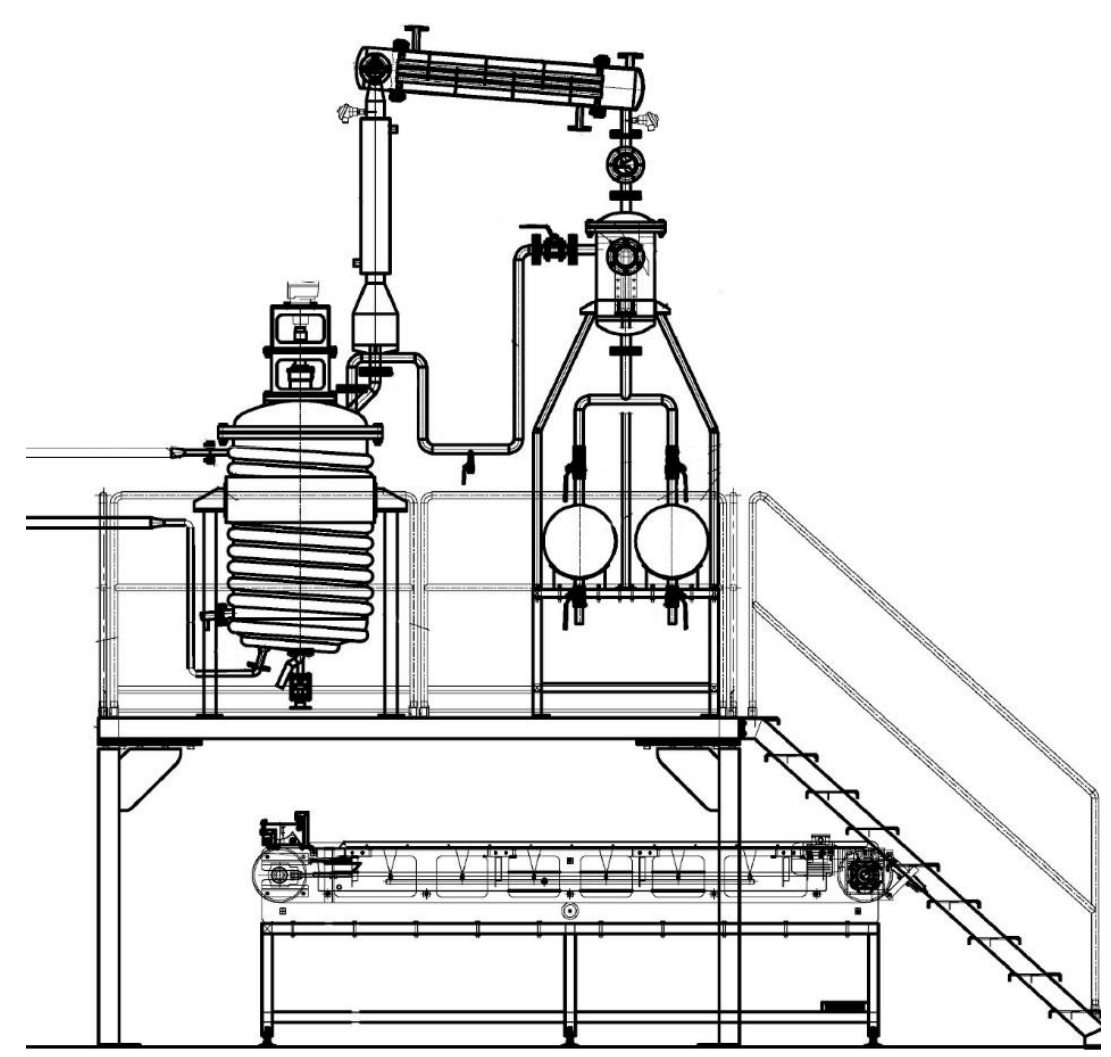

Fig. 2. Pilot extractor for distillation process of turpentine and $\alpha$-terpineol production

Samples from each of the four stages of refining CST and $\alpha$-terpineol sulfur and chlorine content were analyzed by High Definition Energy Dispersive X-Ray Fluorescence (HDXRF).

\section{RESULTS AND DISCUSSION}

\section{Sulfur and Chlorine Content}

The sulfur and chlorine content were determined by HDXRF, as shown in Table 2, which refers to sulphur contents after treatments. Compared to the CST, the sulphur content of the chlorinated CST was reduced from 1260 to $170 \mathrm{ppm}$. Washing with water reduced the sulphur amount by $110 \mathrm{ppm}$, and air oxidation was reduced $110 \mathrm{ppm}$. The distillation process reduced the sulphur content by $29 \mathrm{ppm}$. The $\alpha$-terpineol product had no sulphur content.

Table 2. Sulfur and Chlorine Content of Each Stage of Samples

\begin{tabular}{|c|c|c|c|c|c|}
\hline Material & CST & $\begin{array}{c}\text { Chlorinated } \\
\text { CST }\end{array}$ & Water Wash & Air Oxidation & Distillation \\
\hline Sulfur (ppm) & 1260 & 170 & 110 & 106 & 29 \\
\hline Chlorine (ppm) & - & 4839 & 2905 & 2165 & 121 \\
\hline
\end{tabular}


Various studies on removal of sulfur compounds such as dimethyl disulfide, dimethyl disulfide, methyl mercaptan, etc. found in the CST were compared to the results of the current study. Hydrodesulphurization based on cobalt molybdenum catalyst reduced initial sulphur content from 501 ppm to 55 ppm (Lloyd and Bruce 1994). $\mathrm{H}_{2} \mathrm{O}_{2}$ oxidation and rectification process reduced the sulphur content from 20,000 ppm to $3000 \mathrm{ppm}$ and 70 ppm respectively (Tyurmina et al. 2017). Various refining steps of CST as batch distillation, $\mathrm{N}_{2}$ stripping, sodium hypochlorite treatment, and water wash, respectively, reduced the sulphur content of final products to $1147 \mathrm{ppm}, 552 \mathrm{ppm}, 26 \mathrm{ppm}$, and less than 10 ppm (Hamby et al. 1972). Peracetic acid oxidation process and activated carbon adsorption treatment reduced sulphur content from $38.5 \mathrm{ppm}$ to less than $5 \mathrm{ppm}$ (Sinhmar and Gogate 2020). Quantitative comparison is based on the degree of desulfurization, as the concentration of oxidant (chlorine in current study) and sulfur initiated from the CST used in this process cannot be compared directly all previous studies. However, there is a similarity in the literature that multiple oxidation steps are more effective than a single step oxidation for removing sulfur compounds. Air oxidation led to a decrease of $500 \mathrm{ppm}$ in chlorine content without significant change in sulfur removal.

\section{Chemical Content of CST and $\alpha$-Terpineol with GC-MS}

The composition of the CST is shown in Table 3. Methyl mercaptan, allyl methyl sulfide, dimethyl disulfide, and dimethyl trisulfide were not detected in GC-MS analysis because of low boiling points of the sulphur components. The composition of CST was similar to the literature, but the amount of pinenes in CST was $70 \%$ quantity and final products of refining process DST was $80 \%$ (Table 3). The regional location of the kraft mill, the source of pine species, and the supply season of CST may have the reason for the compositional variance.

Table 3. GC-MS Results of CST and DST

\begin{tabular}{|c|c|c|l|}
\hline \multirow{2}{*}{$\begin{array}{c}\text { Retention Time } \\
(\mathbf{m i n})\end{array}$} & \multicolumn{2}{|c|}{ Quantity (\%) } & \multirow{2}{*}{ Library/ID } \\
\hline 3.28 & CST & DST & \\
\hline 3.86 & 69.93 & 78.39 & $\alpha$-pinene \\
\hline 4.22 & 6.89 & 6.36 & $\beta$-pinene \\
\hline 4.49 & 3.38 & 3.35 & Delta 3-carene \\
\hline 5.30 & 2.40 & 3.42 & D-limonene \\
\hline 5.84 & 2.22 & 0.36 & $\alpha$-terpinolene \\
\hline 6.20 & 0.33 & 0.59 & D-Fenchyl alcohol \\
\hline 6.64 & 0.33 & 0.80 & Isopinocarveol \\
\hline 6.73 & 0.74 & 0.51 & Borneol \\
\hline 6.95 & 0.51 & 0.10 & 1 -4-Terpineol \\
\hline 10.01 & 2.47 & 1.25 & $\alpha$-terpineol \\
\hline 10.91 & 4.54 & 1.12 & $\alpha$-Muurolene \\
\hline & 1.44 & 0.21 & $\alpha$-Cubebene \\
\hline
\end{tabular}

Compounds of $\alpha$-terpineol fractions are given in Table 4 based on GC-MS analysis. The $\alpha$-pinene was converted to the terpin hydrate crystal, then $\alpha$-terpineol was produced. The amount of $\alpha$-pinene in CST (Table 3) was $63.93 \%$ initially, and pinenes were transformed to $\alpha$-terpineol. The main products in the $\alpha$-terpineol, as well as residual monocyclic monoterpenes, remained (Table 4). 
Table 4. GC-MS Results of the Experiment of $\alpha$-Terpineol Conversion from Terpin Hydrate

\begin{tabular}{|c|c|l|}
\hline Retention Time (min) & Quantity (\%) & \multicolumn{1}{|c|}{ Library/ID } \\
\hline 3.50 & 3.80 & a-Fenchene \\
\hline 4.22 & 1.99 & Delta 3-Carene \\
\hline 4.31 & 3.34 & Isocineole \\
\hline 4.54 & 2.51 & D-Limonene \\
\hline 4.76 & 0.22 & $\beta$-Phellandrene \\
\hline 4.90 & 17.19 & $\Gamma$-terpineol \\
\hline 5.35 & 51.45 & $\alpha$-Terpinolene \\
\hline 5.84 & 1.01 & D-Fenchyl alcohol \\
\hline 6.11 & 8.55 & Terpinene-1-ol \\
\hline 6.29 & 2.09 & $\beta$-terpineol \\
\hline 6.56 & 11.13 & Isobornyl acetate \\
\hline 6.79 & 0.42 & 1 -4-Terpineol \\
\hline 7.01 & 4.39 & $\beta$-Fenchyl alcohol \\
\hline 8.68 & 0.07 & Terpin Hydrate \\
\hline 10.79 & 0.11 & $\Gamma$-Cadinene \\
\hline
\end{tabular}

Terpineol formation $16 \mathrm{~h}$ after hydration was investigated by GC/MS analyzes (Table 4). The $\alpha$-pinene and $\beta$-pinene were all transformed to $\alpha$-terpineol. A significant amount of $\alpha$-terpineol, which was found in small amounts in turpentine, was formed as a result of the hydration reaction of $\alpha$-terpineol.

\section{CONCLUSIONS}

1. Results related to refining of crude sulfate turpentine (CST) products were obtained with various process steps from a pilot extractor operation. The refining stages of the CST product were compared with the derivatives products concerning sulphur content. In all cases the greatest increase was achieved by a chlorination process. However, even at constant levels of chlorination, the chlorine content of the product was affected. Even after distillation of the last stage of the process, traces of sulfur and chlorine remained in the product.

2. The purification of sulfate turpentine and the recovery of sulfurous compounds were achieved. This contributed to the closure of the process cycle deficit by producing a sulfate turpentine product. Such a product currently is not industrially produced in Turkey. Progress also was achieved in the direction of zero waste, as well as the avoidance of environmental pollution and malodourous compounds (total reduced sulfur, TRS) obtained as by products.

3. The conversion of terpene as $\alpha$-terpineol was investigated. The main purpose of the study at this stage is to optimize the reaction efficiency by developing an efficient hydration reaction with a short reaction time for the production of $\alpha$-terpineol from CST. 
4. Besides, terpin hydrate production also can be considered as an alternative to refining process. Thus, while the amount of sulfur was reduced by $\alpha$-terpineol conversion, an alternative byproduct was obtained at the same time. Consequently, a kraft mill could remove the amount of sulfur by obtaining alternative byproducts.

\section{ACKNOWLEDGEMENTS}

The author thanks the expertise of terpene chemicals, Chemical Process Eng. Mehmet Emin GULE also to Danış Group, where pilot type operation was conducted.

\section{REFERENCES CITED}

Aguas, I., Alarcón, E., and Villa, A. L. (2020). "Turpentine valorization by its oxyfunctionalization to nopol through heterogeneous catalysis," Heliyon 6(5), article no. e03887. DOI: 10.1016/j.heliyon.2020.e03887

Anonymous (2002). "Current awareness in flavour and fragrance," Flavour Fragr. J. $1(1), 156-163$.

ASTM D 889-58 (1981). "Standard test method for volatile oil in rosin," ASTM International, West Conshohocken, USA.

ASTM D 233-65 (1981). "Standard methods of sampling and testing turpentine," ASTM International, West Conshohocken, USA.

Ávila, M. C., Comelli, N. A., Rodríguez-Castellón, A. J.-L. E., Carrizo Floresa, R., Ponzi, E. N., and Ponzi, M. I. (2010). "Study of solid acid catalysis for the hydration of $\alpha$-pinene," J. Mol. Catal. A Chem. 322(1), 106-112. DOI:

10.1016/j.molcata.2010.02.028

Ballesteros, R., García, D., Bustamante, F., Alarcón, E., and Lapuerta, M. (2020). "Oxyfunctionalized turpentine: Evaluation of properties as automotive fuel," Renewable Energy 162, 2210-2219. DOI: 10.1016/j.renene.2020.10.026

Buisman, G. J. H., and Lange, J. H. M. (2016). "Arizona Chemical: Refining and upgrading of bio-based and renewable feedstocks," in: Industrial Biorenewables: A Practical Viewpoint, P. D. de María (ed.), Wiley, Hoboken, NJ, USA, pp. 21-62: DOI: 10.1002/9781118843796.ch2

Cheremisinoff, N. P., and Rosenfeld, P. E. (2010). "Sources of air emissions from pulp and paper mills," in: Handbook of Pollution Prevention and Cleaner Production: Best Practices in the Wood and Paper Industries, Elsevier, Amsterdam, pp. 179-259, DOI: 10.1016/b978-0-08-096446-1.10006-1

Collins, R.A., and Brunswick, G., (1946). "Refining sulfate terpentine," U.S. Patent 2,409614 2-7.

Drew, J., and Pylant Jr., G. D. (1966). "Turpentine from the pulpwoods of the United States and Canada," Tappi Journal 49(10), 430-438.

Dubey, P., and Gupta, R. (2018). "Influences of dual bio-fuel (Jatropha biodiesel and turpentine oil) on single cylinder variable compression ratio diesel engine," Renewable Energy 115(1), 1294-1302, DOI: 10.1016/j.renene.2017.09.055

Foran, C. D. (1995). "Impact of recent pulp-mill modifications on sulfur contents in crude sulfate turpentine," Tappi Journal 78(6), 93-101.

Ghinet, M., and Orza, N. (1967). "Determination of the yield and quality of crude sulfate 
turpentine in the pulp and paper mill 'Reconstructia'," Celuloza si Hirtie Journal 16(12), 481-485.

Gscheidmeier, M., and Fleig, H. (1996). Turpentines, Ullman's Encyclopedia of Industrial Chemistry, B. Elvers and S. Hawkins (eds.), VCH, New York.

Hamby, C. B., Barrett, C. W., and Derfer, J. M. (1972). "Process for removing sulfur from crude sulfate turpentine or distillate fraction thereof," U.S. Patent 3,660,512.

Hwang, Y., Matsuo, T., Hanakit, K., Suzuki, N. (1994). "Removal of odorous compounds in wastewater by using activated carbon, ozonation and aerated biofilter," Water Res. 28, 2309-2319.

Ilichev, I. S., Radbil, A. B., Shalashova, A. A., Mavrina, E. A., Kozlov, I. A., Ignatov, A.V., and Semenycheva, L. L. (2014). "Turpentine deep purification from sulfur compounds," Вестник Нижегородского Үниверситета 1(1), 110-114.

Izmest'ev, E. S., Rubtsova, S., and Kutchin, A. V. (2019). "Environmental aspects of sulfate turpentine refining (review)," Theoretical and Applied Ecology 1(1), 13-22. DOI: 10.25750/1995-4301-2019-1-012-022

Jennings, W. H. (1939). "Process for refening for sulfate wood terpentine," U.S. Patent 2,283,067.

Kazakov, M. O., Kazakova, M. A., Vatutina, Y. V., Larina, T. V., Chesalov, Y. A., Gerasimov, E. Y., Prosvirin, I. P., Klimov, O. V., and Noskov, A. S. (2020). "Comparative study of MWCNT and alumina supported CoMo hydrotreating catalysts prepared with citric acid as chelating agent," Catalysis Today 357, 221-230, DOI: 10.1016/j.cattod.2019.03.051

Knuuttila, P. (2013). "Wood sulphate turpentine as a gasoline bio-component," Fuel Journal 104(1), 101-108, DOI: 10.1016/j.fuel.2012.06.036

Koppenhoefer, B., Behnisch, R., Epperlein, U., Holzschuh, H., Bernreuther, A., Piras, P., and Roussel, C. (1994). "Enantiomeric odor differences and gas chromatographic properties of flavors and fragrances," Perfumer \& Flavorist Journal 19(5), 1-14.

Leonardos, G., Kendall, D., and Barnard, N. (1969). "Odor threshold determinations of 53 odorant chemicals," Journal of the Air Pollution Control Association 19(2). DOI: 10.1080/00022470.1969.10466465

Linnekoski, J. A., Asikainen, M., Heikkinen, H., Kaila, R. K., Räsänen, J., Laitinen, A., and Harlin, A. (2014). "Production of p-cymene from crude sulphate turpentine with commercial zeolite catalyst using a continuous fixed bed reactor," Organic Process Research and Development 18(11), 1468-1475, DOI: 10.1021/op500160f

Lloyd, B., and Bruce, I.W., (1994). "Hydrodesulfurization of crude alpha-pinene," U.S. Patent 3,312,750.

Miller, F. L. (1970). "Process for producing alpha-pinene of low sulfur content from crude sulfate turpentine," U. S. Patent 3655803A.

Naoum, T., Wouter, B., Jagjit, S. S., and Mukesh, K. (2019). "Renewable chemical feedstock supply network design: The case of terpenes," Journal of Cleaner Production 222, 802-822. DOI: 10.1016/j.jclepro.2019.02.108

Packer, J. E., Robertson, J., and Wansbrough, H. (1998). Chemical Processes in New Zealand, New Zealand Institute of Chemistry, Auckland, New Zealand.

Pakdel, H., Sarron, S., and Roy, C. (2001). " $\alpha$-Terpineol from hydration of crude sulfate turpentine oil," J. Agric. Food Chem. 49(9), 4337-4341. DOI: 10.1021/jf010341b.

Prakoso, T., Putra, I. A., Handojo, L., Soerawidjaja, T. H., Winoto, H. P., and Indarto, A. (2020). "A method to control terpineol production from turpentine by acid catalysts mixing," Heliyon Journal 6(10), article no. e04984. 
DOI:10.1016/j.heliyon.2020.e04984

Prochazka, O., Foy, S., (1958). “Turpentine purification process,” U.S. Patent $3,778,485 \mathrm{~A}$.

Rehman, S., Alhems, L. M., Jadim, R., Al Faraj, B. A., Balasubramanian, K. S., Al Mutairi, K. S., Al-Yemni, A. K., Shinde, D. V., and Al-Hsaien, S. A. (2016). "Maximum acceptable concentrations of dbds, sulphur mercaptan and optimal concentration of passivators for safe and prolonged operation of power transformers," IEEE Transactions on Dielectrics and Electrical Insulation 23(4), 2438-2442. DOI: 10.1109/TDEI.2016.7556523

Santos, M. G., and Morgado, A. F. (2005). "Alfa-terpineol production from refined sulphate turpentine limonene cineol terpinene," in: $2^{\text {nd }}$ Mercosur Congress on Chemical Engineering and $4^{\text {th }}$ Mercosur Congress on Process Systems Engineering, Rio de Janeiro, Brasil.

Sell, C. S. (2006). "Ingredients for the modern perfumery industry," in: The Chemistry of Fragrances, $2^{\text {nd }}$ Ed., D. Pybus and C. Sell (eds.), pp. 52-131, Royal Society of Chemistry, London. DOI: 10.1039/9781847555342-00052.

Sinhmar, P. S., and Gogate, P. R. (2020). "Ultra-deep desulfurization of crude sulfated turpentine using oxidation, adsorption and novel combination approach," Environmental Technology \& Innovation 18(5), DOI: 10.1016/J.ETI.2020.100682

Surburg, H., and Panten, J. (2016). "Common fragrance and flavor materials: preparation, properties and uses," in: Common Fragrance and Flavor Materials: Preparation, Properties and Uses, 6th Ed., H. Surburg and J. Panten (eds.), Wiley-VCH, Weinheim. DOI: 10.1002/9783527693153.

Topsøe, H., Clausen, B. S., and Massoth, F. E. (1996). Hydrotreating Catalysis Science and Technology, Springer-Verlag, New York.

Tyurmina, E. S., Semenycheva, L. L., Mavrina, E. A., Shalashova, A. A., Il'ichev, I. S., Radbil', A. B., and Lazarev, M. A. (2017). "The raw sulfate turpentine purification from sulfur-containing compounds" Bull. High. Educ. Institutions. Lesn. Zhurnal (Forestry journal) 177-185.

Ucar, G., Balaban, M., and Atik, C. (2000). "Composition of sulfate turpentine from Turkey," Holz als Roh - und Werkstoff 58(4), 292-293. DOI: 10.1007/s001070050430

Valkanas, G., and Iconomou, N. (1963). "Reaktionen in der Terpen-Reihe: 1. Mitteilung," Helvetica Chimica Acta 46(3), 1089-1096. DOI: 10.1002/hlca.19630460346

Vickerman, J. C. (2013). "Prologue: ToF-SIMS- An evolving mass," in: ToF-SIMS: Materials Analysis by Mass Spectrometry, J. C. Vickerman and D. Briggs (eds.), IM Publications LLP and SurfaceSpectra Limited, West Sussex, UK, pp. 1-39.

Vital, J., Almeida, V., and Lobo, L. S. (1992). "Kinetic modelling with phase equilibria of $\alpha$-pinene hydration to terpine in isobutanol-water," The Chemical Engineering Journal 50(3), 115-121. DOI: 10.1016/0300-9467(92)80018-6

Wang, M., Huang, Z., Liu, G., Kang, F., (2011). "Adsorption of dimethyl sulfide from aqueous solution by a cost-effective bamboo charcoal," J. Hazard. Mater. 190, 10091015.

Wiecka, Z., Rzelewska-Piekut, M., Cierpiszewski, R., Staszak, K., and Regel-Rosocka, M. (2020). "Hydrometallurgical recovery of cobalt (II) from spent industrial catalysts," Catalysts Journal 10(61), 1-13. DOI: 10.3390/catal10010061 
Williams, C. M., and Whittaker, D. (1971). "Rearrangements of pinane derivatives. Part I. Products of acid catalysed hydration of $\alpha$-pinene and $\beta$-pinene," Journal of the Chemical Society B: Physical Organic 10(1), 668-672. DOI: 10.1039/J29710000668

Article submitted: June 28, 2021; Peer review completed: August 21, 2021; Revised version received and accepted: October 16, 2021; Published: October 20, 2021.

DOI: $10.15376 /$ biores.16.4.8098-8110 